\title{
Impact of PHEVs on Spinning Reserve and Frequency Regulation Market in Smart Grids
}

\author{
Ali Ramzanzadeh Badeleh
}

\begin{abstract}
Plug-in hybrid electric vehicles (PHEVs) are being used in today's smart grid with high penetration. In addition to their main transportation duty, they can be used as a reliable source of energy for the grid at the time of high demand and save money for their owners. Because PHEVs are able to quickly respond to systems need, they can be used for applications such as reserve and frequency regulations. This paper presents a cost optimization study on the effect of PHEVs presence in the reserve and frequency regulations in power grids.
\end{abstract}

Index Terms - Cost, frequency regulation, PHEV, spinning reserve

\section{NOMENClATURE}

$\begin{array}{cl}C_{E n e r g y} & \text { Cost of generated energy by generators } \\ C_{R e g}^{t} & \text { Cost of generated energy by reserve units } \\ C_{S R}^{t} & \text { Cost of generated energy by spinning reserve } \\ C_{P h e v}^{t} & \text { Cost of generated energy by PHEVs at time } t \\ P g_{i}^{t} & \text { Generated power by generator } i \text { at time } t \\ \operatorname{Preg}_{i}^{t} & \text { Frequency regulation power by unit } i \text { at time } t \\ \operatorname{Psr}_{i}^{t} & \text { Spinning reserve power by unit } i \text { at time } t \\ \operatorname{Pphev}_{i}^{t} & \text { PHEV power in bus } i \text { at time } t \\ \operatorname{Pdem}_{i}^{t} & \text { Consumed load power at bus } i \text { at time } t \\ \operatorname{Pg}_{i}^{\text {Max }} & \text { Maximum Generated power by unit } i \\ R R^{t} & \text { Required frequency regulation power at time } t \\ S R^{t} & \text { Required Spinning reserve power at time } t \\ S_{i j}^{t} & \text { Power flow between bus } i \text { and } j \text { at time } t \\ \alpha_{i} & \text { 1 for units with reserve } \\ \operatorname{Preg}_{i}^{\text {max }} & \text { Maximum power of unit } i \text { in frequency } \\ \operatorname{Psr}_{i}^{\text {max }} & \text { regulation } \\ \operatorname{Pphev}_{i}^{\text {ma }} & \text { Maximum power of unit } i \text { in spinning reserve } \\ & \end{array}$

\section{INTRODUCTION}

The conventional power grid has undergone a huge change since it was conceived about a century ago and became a smart grid. Smart grid incorporate technology that allows for two-way communication between the utility and customers [1]. Smart grid comprised of controls, computers, automation, and new technologies and equipment working together, to assist the grid to respond to the quickly changing electric demand. Smart grid can be defined as any advanced technique that enhances the grid capability in generating transmitting and delivering of energy to the customers;
Reference [2] develops a power scheduling for demand response in power grids. In [3], the authors developed a machine learning-based event classification framework to enhance the situational awareness and health monitoring of critical assets in transmission grids. In [4], an effective signal processing based method is proposed to decrease the restoration time of a smart power grid in the case of disturbances. The method reduces the outage costs and increases the customers' satisfaction. In [5], the authors discuss different approaches for security risk management. A frequency security based Energy Management System for a hierarchically controlled grid is proposed in [6]. In [7], the effects of the size and location of distributed generations on loss reduction in smart grids are evaluated. In [8], the authors present a study on the role of energy storage in smart grids.

Combustion engine vehicles have been around for over a century. Several studies have been conducted to optimize the efficiency of these vehicles[9]-[12]. However, due to several factors, such as being environmentally friendly, less noisy, and cheaper fuel, electric vehicles are getting popular every day. According to the International Energy Agency forecasts, the number of electric vehicles on the road around the world will rise to 125 million by 2030 [13]. Plug-in hybrid electric vehicles (PHEVs) have the capability of getting connected to the grid and receive or send energy to it. Several studies have been conducted on the effect of PHEVs in power grids. Das et al. developed a voltage stability analysis in power grids integrated with PHEVs [14]. In [15], the authors investigated the potential impacts of PHEVs on locational marginal prices. In [16], the authors proposed a probabilistic model to improve voltage profile and power factor for unmanaged charging of PHEVs at residential areas [16]. Zhang et al. proposed a dynamic battery modeling for PHEVs in power grids [17].

PHEVs basically have two modes of operations: grid to vehicle $(\mathrm{G} 2 \mathrm{~V})$ and vehicle to grid (V2G). In the G2V mode, the vehicle receives energy from to grid and being charged. On the other hand, in the V2G mode, the vehicle supply energy to the grid and helps it to provide extra energy at peak times [18]. In this fashion, PHEVs can act as a reserve for energy and the customers can save money by participating in a demand response program. PHEVs are also very quick to respond in case of any changes in the grid frequency, and therefore, suitable for frequency regulations.

This paper investigates a study on the PHEVs role in reserve market and frequency regulations in smart grids. The rest of this paper is organized as follows. Section III discusses the parameters in the cost of PHEVs. Section IV defines the objective function. PHEV modeling is explained in Section V. Finally, simulation results and Conclusion are presented in Section VI and VII, respectively. 


\section{Cost Study of PHEVs}

PHEVs can sell their power to the grid by supplying energy to the grid in $\mathrm{V} 2 \mathrm{G}$ mode. The $\mathrm{V} 2 \mathrm{G}$ cost of energy can be calculated using (1)

$$
C=c_{e n} E_{\text {disp }}+c_{a c}
$$

Where $\mathrm{C}$ is the total annual cost, $\mathrm{C}_{\mathrm{en}}$ is the generated energy cost, $\mathrm{E}_{\mathrm{disp}}$ is the amount of annual dispatchable energy, and $\mathrm{C}_{\mathrm{ac}}$ is the annual investment cost.

$E_{\text {disp }}$ can be calculated using (2) as follows

$$
E_{\text {disp }}=R_{d-c} P_{t p l u g}
$$

Where $\mathrm{R}_{\mathrm{d}-\mathrm{c}}$ and $\mathrm{Pt}_{\text {plug }}$ are the resistor in the charging process and power supplied to the grid by the vehicle.

$\mathrm{C}_{\text {en }}$ can be calculated using (3)

$$
c_{e n}=\frac{c_{p e}}{\eta_{c o n v}}+c_{d}
$$

Where $C_{p e}$ is the cost of purchased energy, $C_{d}$ is the cost of required equipment for charging in $\$ / \mathrm{kWh}$, and $\eta_{\text {conv }}$ is the efficiency of the battery.

$\mathrm{C}_{\mathrm{d}}$ can be defined as:

$$
c_{d}=\frac{c_{b a t}}{L_{E T}}
$$

Where $\mathrm{C}_{\mathrm{bat}}$ is the battery cost in $\$$ and $\mathrm{LET}_{\mathrm{ET}}$ is the life span of the battery. In the analysis, if the cars life span is shorter

\begin{tabular}{|c|c|c|}
\hline Parameters & Value & Unit \\
\hline $\mathbf{R}_{\mathrm{d}-\mathrm{c}}$ & 0.1 & \\
\hline $\mathbf{P}$ & 4 & $\mathrm{~kW}$ \\
\hline$t_{\text {plug }}$ & 5343 & $\mathrm{H}$ \\
\hline Cpe & 0.08 & $\$ / \mathrm{kWh}$ according CAISO \\
\hline$\eta_{\text {conv }}$ & 0.92 & \\
\hline Cd & 0 & \\
\hline Cen & 0.086 & $\$ / \mathrm{kWh}$ for one day \\
\hline Cen & 0.055 & $\$ / \mathrm{kWh}$ (wholesale) \\
\hline
\end{tabular}
than battery life span $C_{d}$ is negligible [19].

TABLE I shows the parameters values for the PHEVs [19].

\section{OBJECTIVE FunCTION}

The objective function is defined as the minimization of the costs of generated energy and spinning reserve as shown in (5). This optimization problem must be solved with respect to several constraints such as load generation balance equation, line congestion, and maximum power of the vehicle. The cost optimization problem is expressed as follows

$$
\begin{gathered}
\text { Minimize }\left\{C_{\text {Energy }}+C_{\text {Reserve }}\right\} \\
C_{\text {Energy }}=\sum_{i} \sum_{t} C_{i}^{t}\left(P g_{i}^{t}\right) \\
C_{\text {Reserve }}=\sum_{i} \sum_{t}\left\{\begin{array}{c}
C_{\text {Reg }}^{t}\left(\text { Preg }_{i}^{t}\right) \\
+C_{S R}^{t}\left(P s r_{i}^{t}\right)+C_{P h e v}^{t}\left(\text { Pphev }_{i}^{t}\right)
\end{array}\right\}
\end{gathered}
$$

St:

$$
\begin{aligned}
& \sum_{i}\left\{P g_{i}^{t}+\operatorname{Pphev}_{i}^{t}+\alpha_{i} P s r_{i}^{t}+\alpha_{i} \operatorname{Preg}_{i}^{t}\right\}=\operatorname{Pdem}_{i}^{t} \\
& P g_{i}^{t}+\alpha_{i} P s r_{i}^{t}+\alpha_{i} \operatorname{Preg}_{i}^{t} \leq P g_{i}^{M a x} \\
& R R^{t} \leq \sum_{i} \operatorname{Pphev}_{i}^{t}+\alpha_{i} \operatorname{Preg}_{i}^{t} \\
& S R^{t}+R R^{t} \leq \sum_{i} \operatorname{Pphev}_{i}^{t}+\alpha_{i} \operatorname{Preg}_{i}^{t}+\alpha_{i} \operatorname{Psr}_{i}^{t} \\
& \left|S_{i j}^{t}\right| \leq S_{i j}^{\max } \\
& 0 \leq \operatorname{Preg}_{i}^{t} \leq \operatorname{Preg}_{i}^{\max } \\
& 0 \leq P s r_{i}^{t} \leq P s r_{i}^{\max } \\
& 0 \leq \text { Pphev }_{i}^{t} \leq \text { Pphev }_{i}^{\max }
\end{aligned}
$$

\section{PHEVS MODELING}

In this study, different penetration level of PHEVs in the grid are considered. The number of vehicles that are interacting with the network are different during the day. Fig. 1 shows the availability of PHEVs during the day. It is assumed that the total number of PHEVs in the grid is 12500 . Table II shows different characteristics of PHEVs in the fleet. As it can be seen, PHEVs are Chevy Volts, with maximum battery capacity of $16 \mathrm{kWh}$. The voltage, current, and power ratings for charging are $220 \mathrm{~V}, 16 \mathrm{~A}$, and $4 \mathrm{~kW}$. Three penetration levels are considered in this study; $10 \%, 20 \%$, and $50 \%$.

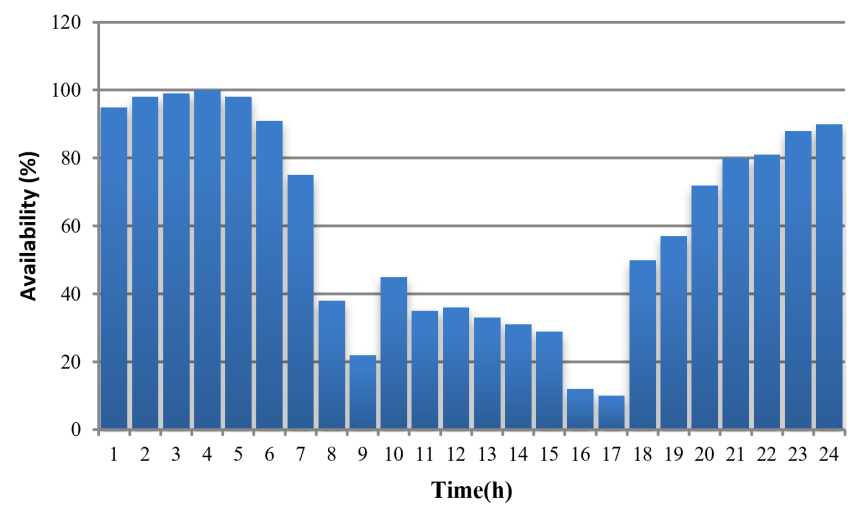

Fig.1 PHEVs availability during the day

TABLE II. SYSTEM PARAMETERS

PHEV

Chevy Volt

\begin{tabular}{|cc|}
\hline Battery & Li-ion \\
\hline Maximum Capacity & $16 \mathrm{kWh}$ \\
\hline Voltage & $240 \mathrm{~V}$ \\
\hline Current & $16 \mathrm{~A}$ \\
\hline Power & $4 \mathrm{~kW}$ \\
\hline
\end{tabular}




\section{Simulation Results}

The simulation has been performed on the IEEE 5 bus test system. The system configuration and parameters are presented in Fig. 2, and Table III, respectively. In this network, the values are per unit based on $100 \mathrm{MW}$ and 200 $\mathrm{kV}$. Table IV shows the generating units cost parameters. Generator 1 and 2 participate in spinning reserve market and frequency regulation. The required reserve value for the network is considered $100 \mathrm{MW}$ and for frequency regulation is considered $28.8 \mathrm{MW}$ which makes up to $128.8 \mathrm{MW}$ total which is $5 \%$ of total load [20]. The cost function for units that participate in spinning reserve market are calculated the same as the generators functions and the units that participate in frequency regulation is half of those units. All the codes are performed in GAMS.

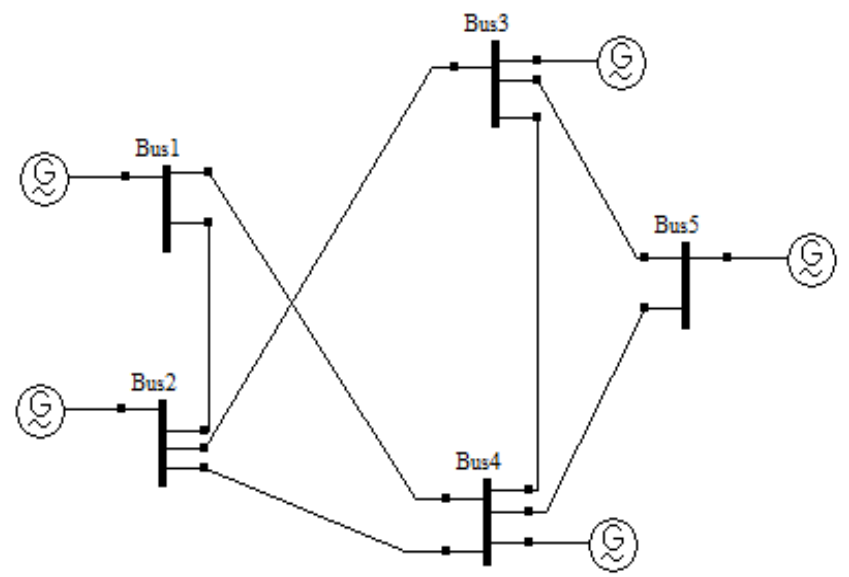

Fig.2. IEEE 5 bus test system

\begin{tabular}{ccccc}
\multicolumn{5}{c}{ TABLE III. IEEE 5 BUS SYSTEM PARAMETERS } \\
\hline From bus & To bus & $\mathbf{R}(\mathbf{p u})$ & $\mathbf{X}(\mathbf{p u})$ & $\mathbf{P}^{\mathbf{m a x}}(\mathbf{p u})$ \\
\hline 1 & 2 & 0.0147 & 0.168 & 3.00 \\
\hline 1 & 4 & 0.0108 & 0.126 & 3.55 \\
\hline 2 & 3 & 0.0185 & 0.210 & 3.00 \\
\hline 3 & 4 & 0.0294 & 0.296 & 3.00 \\
\hline 3 & 5 & 0.0221 & 0.213 & 3.00 \\
\hline 4 & 5 & 0.0108 & 0.104 & 4.50 \\
\hline 2 & 4 & 0.0105 & 0.100 & 3.60 \\
\hline
\end{tabular}

TABLE IV. GENERATING UNITS PARAMETERS

\begin{tabular}{cccccc}
\hline Bus & $\mathbf{a}\left(\mathbf{\$} / \mathbf{M W}^{\mathbf{2}} \mathbf{h}\right)$ & $\mathbf{b}(\mathbf{\$} / \mathbf{M W h})$ & $\mathbf{c}(\mathbf{\$} / \mathbf{h})$ & $\mathbf{P g}^{\mathbf{m a x}}(\mathbf{M W})$ & $\begin{array}{c}\mathbf{P g}^{\mathbf{m i n}} \\
\mathbf{( M W )}\end{array}$ \\
\hline 1 & 0.040 & 20 & 0 & 460 & 0 \\
\hline 2 & 0.030 & 21 & 0 & 500 & 0 \\
\hline 3 & 0.045 & 25 & 0 & 500 & 0 \\
\hline 4 & 0.040 & 56 & 0 & 500 & 0 \\
\hline 5 & 0.040 & 57 & 0 & 500 & 0 \\
\hline
\end{tabular}

\section{A. Impact on the Spinning Reserve Cost and Power}

Considering spinning reserves in the network are a major component in increasing system reliability. In our consideration, both generators and PHEVs need to be included. Fig. 3 shows the PHEVs and generators participation in the reserve market. As it can be seen from the figure, as PHEVs penetration increases, the vehicles' penetration in the reserve market increases. Although, their participation in the reserve market is not high enough due to their high prices.

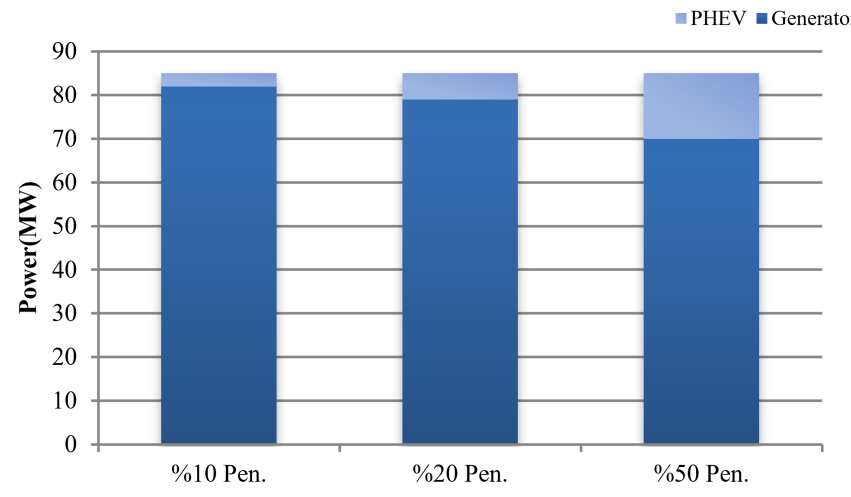

PHEV's Penetration(\%)

Fig.3. Reserve power comparison for PHEVs and generators for different penetration levels

Table V shows that with the increase in the units' participation, the overall cost of ancillary services increases, too. This increase in the cost is due to the cost that PHEVs incur in their V2G mode.

$\begin{array}{llll}\text { TABLE V. UNITS COST FOR DIFFERENT PENETRATION LEVEL FOR RESERVE } \\ & \mathbf{1 0 \%} \text { Pen. } & \mathbf{2 0 \%} \text { Pen. } & \mathbf{5 0 \%} \text { Pen. } \\ \text { Generators } & \$ 84396 & \$ 81194 & \$ 71661 \\ \text { PHEVs } & \$ 8057 & \$ 16115 & \$ 40287 \\ \text { Total Cost } & \$ 92453 & \$ 97309 & \$ 111948\end{array}$

As it can be seen, as the penetration level increases, the generator cost decrease while the PHEVs cost increase and the total cost increases.

Fig. 4 shows the relation between the penetration level of PHEVs and the price. As it can be seen, for prices around $0.021 \$ / \mathrm{kWh}$ the price for vehicles penetration is the same as reserve units. As this price decreases the vehicle penetration increases and therefore the cost decreases. Likewise, as the price increases, the vehicle penetration decreases to the point that for the price of $0.024 \$ / \mathrm{kWh}$ the penetration will be zero.

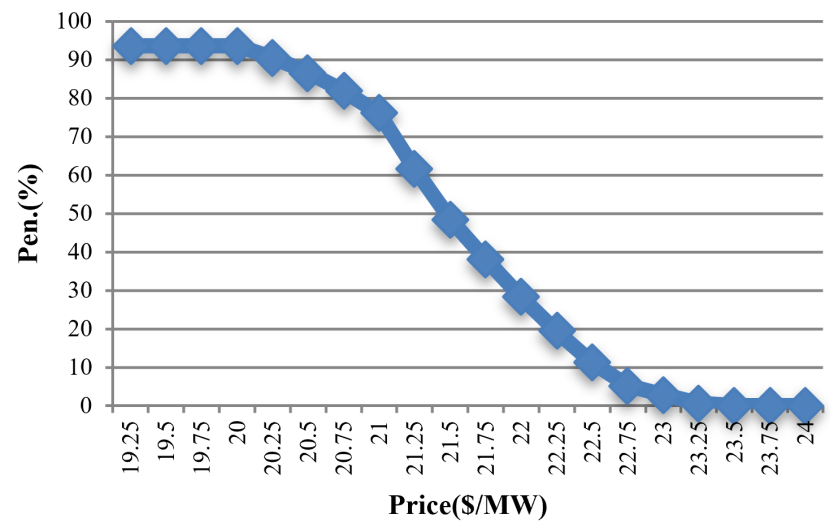

Fig. 4. PHEV penetration with respect to different prices

\section{B. Impact on Frequency Regulation Cost and Power}

In simulations for studying the impact of PHEVs on frequency regulation, a number of vehicles are assumed that compete in a market with generating units. The summation of these two, compose the required power for frequency regulation. The frequency regulation signals used in this 
paper are taken from California market [21]. Fig. 5 shows the reserve units and PHEVs in the market. In high penetrations, PHEVs have more participation in the market.

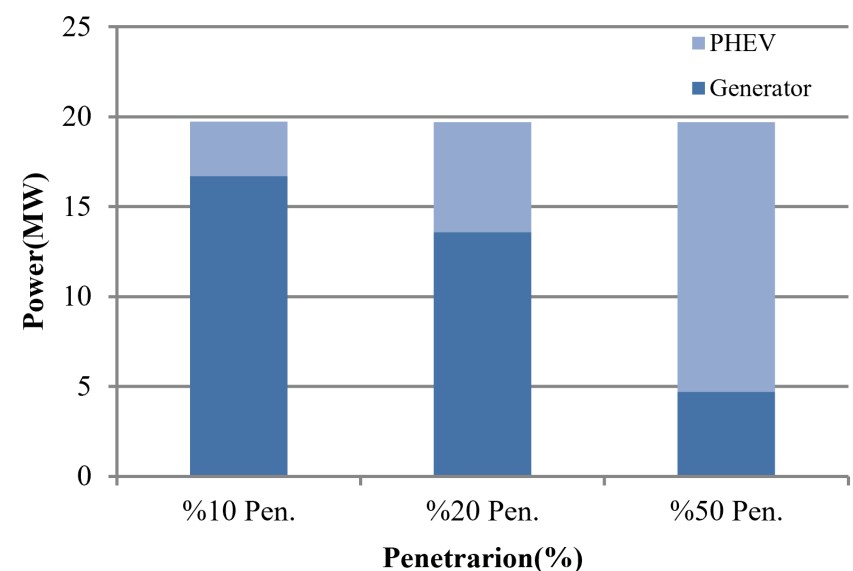

Fig.4. Frequency regulation power comparison of PHEVs and generators for different penetration levels

Table VI shows the cost of the units for different penetration level for frequency regulation. As it can be seen as the penetration level increases, the generators cost decreases while the PHEVs cost increases. This shows the non-competitiveness of PHEVs costs in the frequency regulation market. In other words, the PHEVs presence causes an increase in the system costs, and therefore, an increase in participation cost in the frequency regulation market.

\begin{tabular}{llll}
\multicolumn{4}{r}{ TABLE VI. UNITS COST FOR DIFFERENT PENETRATION LEVEL FOR } \\
& \multicolumn{4}{c}{ FREQUENCY REGULATION } \\
& $\mathbf{1 0 \%}$ Pen. & $\mathbf{2 0 \%}$ Pen. & $\mathbf{5 0 \%}$ Pen. \\
\hline Generators & $\$ 8144$ & $\$ 6637$ & $\$ 2802$ \\
PHEVs & $\$ 8057$ & $\$ 16115$ & $\$ 40287$ \\
Total Cost & $\$ 16201$ & $\$ 22752$ & $\$ 43089$
\end{tabular}

\section{CONCLUSION}

Ancillary services for ensuring security and reliability of the grids are essential. Spinning reserve and frequency regulation are among two major ancillary services. What is very important in these services is the quick response and low cost. Plug-in hybrid electric vehicles (PHEVs) can participate in these services due to their availability and fast response time. In this paper, the impact of PHEVs in spinning reserve market and frequency regulation are investigated. Based on the availability of vehicles and their participation in an area, their participation in the market are determined. It is shown that in both markets, PHEVs increase the costs while in frequency regulation market it is more drastic. The reason for the high costs is not deploying these resources at peak times and their usage time which will decrease with the increase in lifespan of batteries and usage of these resources. With the advancement in technology and lowering the cost of PHEVs they can be used as a reliable source for spinning reserve and frequency regulation market. The biggest problem with PHEVs beside their high costs are their high usage time in trips and not being available during peak hours.

\section{REFERENCES}

[1] A. Ghasemkhani, A. Anvari-Moghaddam, J. M. Guerrero, and B. Bak-Jensen, "An efficient multi-objective approach for designing of communication interfaces in smart grids," in PES Innovative Smart Grid Technologies Conference Europe (ISGT-Europe), 2016 IEEE, 2016, pp. 1-6.

[2] Deilami, S., Masoum, A. S., Moses, P. S., \& Masoum, M. A. (2011). Real-time coordination of plug-in electric vehicle charging in smart grids to minimize power losses and improve voltage profile. IEEE Transactions on Smart Grid, 2(3), 456-467.

[3] M. Khoshdeli, I. Niazazari, R. J. Hamidi, H. Livani, and B. Parvin, "Electromagnetic transient events (EMTE) classification in transmission grids," 2017 IEEE Power \& Energy Society General Meeting, 2017.

[4] O. A. Gashteroodkhani, M. Majidi, M. S. Fadali, M. Etezadi-Amoli, E. M. Amiri, "A Protection Scheme for Microgrids Using Time-Time matrix Z-score Vector", International Journal of Electrical Power and Energy Systems, vol. 110, pp. 400-410, 2019.

[5] Liu, J., Xiao, Y., Li, S., Liang, W., \& Chen, C. P. (2012). Cyber security and privacy issues in smart grids. IEEE Communications Surveys \& Tutorials, 14(4), 981-997.

[6] S. Aznavi, P. Fajri, M. Benidris and B. Falahati, "Hierarchical droop controlled frequency optimization and energy management of a gridconnected microgrid," in 2017 IEEE Conference on Technologies for Sustainability (SusTech), Phoenix, AZ, USA, 2017, pp. 1-7.

[7] A. Forooghi Nematollahi, A. Dadkhah, O. Asgari Gashteroodkhani, and B. Vahidi, "Optimal sizing and siting of DGs for loss reduction using an iterative-analytical method," Journal of Renewable and Sustainable Energy, vol. 8, no. 5, p. 055301, 2016.

[8] Roberts, B. P., \& Sandberg, C. (2011). The role of energy storage in development of smart grids. Proceedings of the IEEE, 99(6), 11391144 .

[9] Van Blarigan, P., \& Keller, J. O. (1998). A hydrogen fuelled internal combustion engine designed for single speed/power operation. International Journal of Hydrogen Energy, 23(7), 603-609.

[10] Bellinger, S. M. (2005). U.S. Patent No. 6,944,532. Washington, DC: U.S. Patent and Trademark Office.

[11] Nasrolahzadeh, N., Fard, M., Tatari, M., \& Mahjoob, M. (2013). Automotive Concept Modelling: Optimization of the Vehicle NVH Performance. In Proceedings of the FISITA 2012 World Automotive Congress (pp. 365-376). Springer, Berlin, Heidelberg.

[12] Takahashi, D., Nakata, K., Yoshihara, Y., Ohta, Y., \& Nishiura, H. (2015). Combustion development to achieve engine thermal efficiency of $40 \%$ for hybrid vehicles (No. 2015-01-1254). SAE Technical Paper.

[13] https://www.cnbc.com/2018/05/30/electric-vehicles-will-grow-from3-million-to-125-million-by-2030-iea.html

[14] Das, T., \& Aliprantis, D. C. (2008, November). Small-signal stability analysis of power system integrated with PHEVs. In 2008 IEEE Energy 2030 Conference (pp. 1-4). IEEE.

[15] Wang, L. (2008, November). Potential impacts of plug-in hybrid electric vehicles on locational marginal prices. In 2008 IEEE Energy 2030 Conference (pp. 1-7). IEEE.

[16] Niazazari, I., Khatami, R., Abyaneh, H. A., \& Farsani, E. A. (2014, November). Voltage Profile and Power Factor Improvement in PHEV Residential Charging Using a Probabilistic Model in a Smart Grid. In Proceedings of the 2014 IEEE Electrical Power and Energy Conference (pp. 159-164). IEEE Computer Society.

[17] Zhang, H., \& Chow, M. Y. (2010, July). Comprehensive dynamic battery modeling for PHEV applications. In iEEE PES General Meeting (pp. 1-6). IEEE.

[18] Kisacikoglu, M. C., Ozpineci, B., \& Tolbert, L. M. (2010, February). Examination of a PHEV bidirectional charger system for V2G reactive power compensation. In 2010 Twenty-Fifth Annual IEEE Applied Power Electronics Conference and Exposition (APEC) (pp. 458-465). IEEE.

[19] W. Kempton and J. Tomic "Vehicle-to-grid power fundamentals: Calculating capacity and net revenue", Journal of Power Sources, vol.144, 268-279, 2005.

[20] F.Stacke, P.Cuervo, "Integrated Pool/Bilateral/Reserve Market Operation Under Pay-as-Bid Pricing", Electricity Market,5th International Conference on European, pp.1-8, May.2008.

[21] http://www.caiso.com 